\title{
Evidence against instantaneous transfer of spatial knowledge in the house mouse (Mus musculus)
}

\author{
SOFYAN H. ALYAN \\ University of Kansas, Lawrence, Kansas
}

\begin{abstract}
Perceptual vector deduction (instantaneous transfer) is the ability of a displaced animal to deduce the vector toward home from a novel location solely on the basis of its current perception of a previously learned constellation of landmarks. Different groups of house mice, Mus musculus, subjected to different treatments, were tested for such an ability. The tests were done on a circular arena, $1.5 \mathrm{~m}$ in diameter, that had a nest attached to the periphery. Mice that were confined to the nest for $24 \mathrm{~h}$, with a full view of the room, failed to home accurately when deprived of the opportunity of integrating the path from the nest to the center of the arena. Similar failures were obtained when the mice were tested after they had freely explored an adjacent arena for $24 \mathrm{~h}$, exposed to the same distal landmarks. However, the mice were able to home after being passively transported from the nest to the center of the arena. Free exploration of the test arena for $24 \mathrm{~h}$ improved homing in terms of directness and speed of locomotion toward the nest. Shuttling the mice 10 times between the nest and the release point in the center of the arena, in addition to 24-h free exploration, did not improve subsequent homing accuracy over that obtained from 24-h free exploration. In conclusion, the mice were unable to perceptually deduce a homing vector, and homing was improved by movement through the part of the environment that was used for homing.
\end{abstract}

Tolman (1948) concluded that rats organize their knowledge about the environment in what he called a "cognitive map"- a representation of spatial relations among different places. Such a map would enable the rats to plan and execute novel shortcuts when moving from one place to another. This concept was further elaborated by O'Keefe and Nadel (1978), who presented a more formal definition of such a map-a memory map of an environment that is composed of a set of place representations connected by representations of distances and directions (Nadel, 1991; O'Keefe, 1991a, 1991b; O'Keefe $\&$ Nadel, 1979). The hippocampus was the proposed neural substrate for building such a map (O'Keefe \& Nadel, 1978).

One prediction of O'Keefe and Nadel's cognitive map hypothesis (Morris, 1981) is that there is instantaneous transfer of spatial knowledge from a familiar location to a novel location that shares some or all visual landmarks with the familiar one. Instantaneous transfer can be defined as the ability to compute and execute novel homing vectors to reach particular goals. This homing vector is computed from information about the constellations of landmarks that have been viewed from different locations in the same environment. I shall call such a hypothetical ability perceptual vector deduction.

\footnotetext{
The author thanks Rudolf Jander for critical readings of several earlier drafts of the manuscript. I am also grateful for the helpful comments from the members of the Division of Neural Systems, Memory and Aging at the University of Arizona, Donald Wilson, David Touretzky, Joe Mendelson, A. Etienne, and two anonymous reviewers. Correspondence should be addressed to S. Alyan, ARL, Div. Neural Systems, Memory and Aging, University of Arizona, Tucson, AZ 85724.
}

The favored experimental paradigm for testing perceptual vector deduction has been the Morris water tank or water maze (Morris, 1981), in which rats are trained to swim to a platform hidden just underneath the surface of milky water after being placed into a tank facing the wall at some arbitrary point. Over repeated training trials, the rats become very efficient in reaching the platform in a straight line from any release point. On test trials, the rats are released at new start points after the platform has been removed.

Several criteria (latency to reach the platform, deviations from the straight line connecting the platform to the novel release point, distance traveled, and time spent in the quadrant where the hidden platform was placed) were used to evaluate the rats' navigational performance. If the rat, never having experienced the path connecting the novel release point with the platform, swam straight to the platform, Morris (1981) inferred that it showed instantaneous transfer, or that it had a true cognitive map in the sense defined by O'Keefe and Nadel (1978). Such a cognitive map, it was assumed, must have been formed during training in order for the rat to reach the platform from the original starting points. That is, the rat acquired a complete cognitive representation of the environment on the basis of incomplete viewing of that environment. With such a knowledge, a rat, viewing that environment from a novel vantage point, should have no difficulties planning trajectories to a goal, since the representation is in a form that is independent of a particular experience with the novel release site (Keith \& McVety, 1988; O'Keefe \& Nadel, 1978). Sutherland and Linggard (1982), and later Keith and McVety, reported that rats in a Morris tank were 
able to exhibit instantaneous transfer in a novel environment from being placed on the platform. The rats were able to do this without prior exploratory experience in that environment, provided that they had knowledge of procedural aspects of the task (Keith \& McVety, 1988).

Similar predictions about perceptual vector deduction can be drawn from the hypotheses about the construction of the cognitive maps, as proposed by Gallistel (1990a, 1990b) and O'Keefe (1990, 1991b). However, inferring perceptual vector computation by the rat was called into question (Sutherland, Chew, Baker, \& Linggard, 1987), and several better-controlled investigations were stimulated (see Sutherland \& McDonald, 1990; Whishaw, 1991), which raised further doubts about the existence of instantaneous transfer.

Specifically, the rats in the Morris water task usually had the opportunity to freely swim around in the tank prior to testing, as was pointed out by Sutherland et al. (1987). Sutherland et al. proposed that, during exploratory swimming, the rats could have associated many local views of landmarks with appropriate swimming and movement patterns. Therefore, when the rats were placed into the tank at a point that they had visited while freely swimming, all that they needed to recall was a previously experienced movement pattern that would take them to the hidden platform. This alternative, exploration-based hypothesis that proposes reaching a goal by recalling a past movement pattern associated with a local view was first proposed by McNaughton (1989; see also Sutherland \& Rudy, 1989). This proposal is supported by results from several experiments suggesting that computation of, or remembering, a homing vector could be demonstrated only after the rats had swimming experience in the pool (Chew, Sutherland, \& Whishaw, 1989; Morris, 1981; Sutherland \& Linggard, 1982; Sutherland et al., 1987; Whishaw, 1991). Rats without previous exploration of the tank arrived at the platform less accurately (defined as a straight trajectory in minimum time; see Chew et al., 1989; Whishaw, 1991) than did rats that had had this opportunity.

There still remains one unresolved issue concerning the inference that animals deduce a goal vector. They might appear to deduce perceptual vectors, but in reality they may be deducing a goal vector by motor vector deduction: active or passive path integration (also called dead reckoning; $\mathrm{H}$. Mittelstaedt \& M. L. Mittelstaedt, 1982; Potegal, 1982). Path integration is defined as a running computation of a vector leading to a starting point based on recording all displacements (Alyan \& Jander, 1994; H. Mittelstaedt \& M. L. Mittelstaedt, 1982; R. Wehner \& S. Wehner, 1990). Path integration, a mechanism not explicitly included in several classifications of navigational phenomena (O'Keefe \& Nadel, 1978; Sutherland \& Dyck, 1984; Whishaw \& Mittleman, 1986), enables the animal to compute a totally novel homing vector in a totally unfamiliar area (R. Wehner \& Srinivasan, 1981). Path integration is also a flexible mechanism that allows the animal to negotiate obstacles encountered and to proceed in the original direction it was following (Gallistel, 1990a; R. Wehner, 1983).

The rat in a Morris water tank, displaced from the hidden platform to a novel starting point at the side wall, might get insight into the spatial solution by passive path integration while being displaced. That rodents are indeed capable of some passive path integration, particularly passive rotations, has been amply shown by the work of Etienne and her colleagues, who studied golden hamsters under various conditions (Etienne, 1980, 1992; Etienne, Hurni, Maurer, \& Seguinot, 1991; Etienne, Lambert, Reverdin, \& Teroni, 1993; Etienne, Maurer, \& Saucy, 1988; Etienne, Teroni, Hurni, \& Portenier, 1990; Etienne, Teroni, Maurer, Portenier, \& Saucy, 1985). Integration of passive rotation was also demonstrated in the house mouse in a fully illuminated environment (Alyan \& Jander, 1994). It should be pointed out, however, that there is little empirical evidence that rodents can integrate passive translatory displacements (H. Mittelstaedt \& M. L. Mittelstaedt, 1982). Rats in a Morris water tank might need to integrate rotation and translation of their passive transport in order to find the platform by path integration.

Most of the conclusions about instantaneous transfer that are based on experiments with the Morris water tank do not explore the possibility of passive path integration for rats' passive displacement (Chew et al., 1989; Eichenbaum, Stewart, \& Morris, 1990; Keith \& McVety, 1988; Morris, 1981, 1983, 1984; Schenk \& Morris, 1985; Sutherland \& Linggard, 1982). Yet, in some recent studies (e.g., Sutherland \& McDonald, 1990; Whishaw, 1991), passive path integration was controlled for by leaving the rats in their home cages for a few minutes before placing them into the water. However, even then the rats might have integrated the passive transport from the platform to their cages and then from the cages to the starting locations (Stahl \& Ellen, 1974, p. 601).

The purpose of the present work was to determine whether mice can form a cognitive representation of their environment on the basis of viewing it from a single location (Keith \& McVety, 1988) and under conditions designed to reliably eliminate active and passive path integration. Also, the contribution of passive and active path integration to their navigation capability was investigated. This was done by using a novel method that had three advantages. First, it avoided the problem that, for rats and mice, swimming might not be as easy as walking (as noted by Whishaw, 1991, p. 101, and Morris, 1981). Second, in all the experiments, two strong motivations in the mice were exploited: motivation to find and "hide" inside the nest, and motivation to retrieve their displaced pups (Alyan \& Jander, 1994; M. L. Mittelstaedt \& H. Mittelstaedt, 1980). Third, the final direction taken by the mice was easily recorded.

As mentioned above, the house mouse, Mus musculus, was chosen because the spatial abilities of this rodent have been much less studied than those of rats or hamsters. In addition, the spatial orientation of the house 
mouse proved to be a behavioral system that could be efficiently analyzed (Alyan \& Jander, 1994).

\section{GENERAL METHOD}

\section{Animals}

Captive-reared, fully pigmented (gray) female house mice were used in all the experiments. The mice were housed in transparent living cages with a ground floor of either $25 \times 50 \mathrm{~cm}$ or $25 \times$ $18 \mathrm{~cm}$. All the mice had pine shavings as bedding and were provided with food and water ad lib. Training and testing were conducted during the light portion (0900-1500 h) of a 12:12-h light:dark cycle. Experimentally naive mice were used for each trial, and each mouse was tested not longer than $30 \mathrm{~min}$.

\section{Arenas and Surroundings}

During all the experiments, the experimental room was illuminated by natural light from two large windows on the south side and from the ceiling by standard fluorescent tubes. There were three arenas. The first was a circular arena located in the center of the room; this was the "test arena." A second, 1-m-diam. circular arena (not used in the present experiments) was placed in front of one window; a third, square-table arena, $110 \times 230 \mathrm{~cm}$, was located in front of the other window (see Figure 1). Both of these additional arenas were about $110 \mathrm{~cm}$ above the floor level and were placed on one side of the central test arena. The table arena was about $1.2 \mathrm{~m}$ to the southeast of the test arena. Additional pieces of furniture, as well as several pieces of black cardboard that were hung on the walls, offered additional landmarks for the homing mice.

The circular test arena had a diameter of $1.5 \mathrm{~m}$ and stood $60 \mathrm{~cm}$ above the floor. Its surface was painted with a layer of polyurethane mixed with sand to provide texture. This allowed thorough cleaning by wiping with a wet towel before each test.

A 4-cm-diam. hole in the floor, close to the periphery of the arena, gave access to the subsurface nest box (the home base). To confine the mice inside the arena, its circumference was fenced off to a height of $50 \mathrm{~cm}$ with a clear Plexiglas sheet. Control experiments demonstrated that the mice were able to see and use the distal visual cues outside the arena (see also Alyan \& Jander, 1994). The arena rested on ballpoint bearings, permitting rapid rotation about the center by means of handlebars on the outside. A central

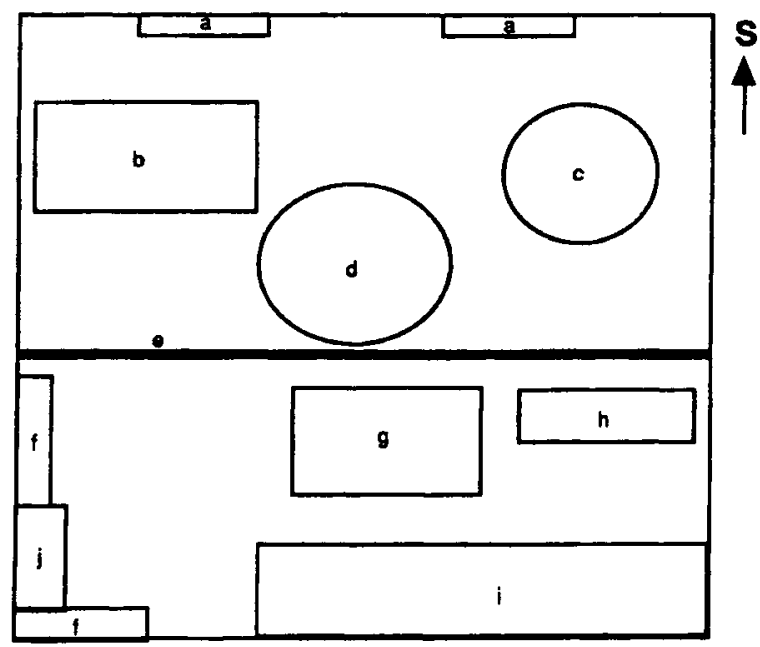

Figure 1. The layout of the experimental room: window (a), table arena (b), circular arena (c; not used in the present experiments), experimental circular arena (d), fence (e; $60 \mathrm{~cm}$ high), door (f), desk (g), bookshelves (h), storing cabinet (i), and sink (j). circular platform ( $20 \mathrm{~cm}$ in diameter) in the arena was designed so that it could rotate with the arena or could stay fixed when the arena was rotated around it. The surface of the central platform was level with the floor of the arena.

The position of the nest box outside the arena's periphery provided easy access to the mice and their pups. The nest box, made of black Plexiglas, was $10 \times 10 \times 10 \mathrm{~cm}$. A $5 \times 1 \mathrm{~cm}$ slot in the floor allowed the mice to dispose of their feces, thus keeping the nests fairly clean. The removable top of the nest was made of a black, slotted metal sheet to facilitate air circulation. Shredded pieces of paper towel served as nesting material

In all the experiments, the mice could see the observing person, who remained at a fixed point relative to the arena, except when removing or releasing the mice.

\section{Procedure}

Prior to testing, each mouse, except when mentioned, was housed for $24 \mathrm{~h}$ in the nest box attached to the circular experimental arena. From the nest box, some mice had access to the whole arena, and others had access only to an area around the exit hole of the nest.

In order to prevent passive path integration while displacing the mice, each individual was taken from its nest, placed on a cardboard sheet that was on a stool beneath the nest, and was then covered by a wooden box $(15 \times 15 \times 10 \mathrm{~cm})$. These were precautions to prevent the mice from seeing any landmark once outside the arena. Then each boxed-in mouse was hand carried and slowly rotated, around the floor for $2 \mathrm{~min}$. After this rotation procedure, and during the absence of the mouse, the arena was sprayed with water that had highly diluted disinfectant and was wiped dry. Then the cardboard with the boxed-in mouse was placed into the center of the arena. During the box placement, the center was approached from different compass directions for different mice. Then the arena, together with the mouse inside the box, was rotated for 7-10 full turns (one turn per 4-5 sec). The cardboard was then pulled from underneath the box in different directions for different mice.

Finally, in order to stimulate (motivate) homing, 1 or 2 pups, now removed from the nest to another location, were lowered through the hole in the roof of the wooden box. A hard plastic sheet $(15 \times 15 \mathrm{~cm})$, painted dark gray, was placed on the top of the roof. The whole box was then lifted up and removed after a lag of 2-3 sec. The experimenter then sat at the designated place while the mouse was still in the center. The subsequent movement of the mice was videotaped from above the center of the arena, until the mice reached the nest.

Exposure to open space and the presentation of 1 pup made use of two kinds of motivations First, the mice would be motivated to hide in their nest (see also Barnes, 1988). Second, the mice would be motivated to return their pups to the nest (see Alyan \& Jander, 1994).

\section{Data Analysis}

The distance traveled by each mouse away from the center, as well as latency and directions were extracted from the taped records. The time spent to reach the nest from the center of the arena was recorded by using a stopwatch. The paths were copied on paper and their lengths were measured by tracing. Directions were recorded when the head of a mouse crossed a circle $5 \mathrm{~cm}$ from the periphery, which is $70 \mathrm{~cm}$ from the center. Angles were measured clockwise from $0^{\circ}-360^{\circ}$, with $0^{\circ}$ being the nest direction before rotation.

To test for directional tendencies, circular statistics were used (Batschelet, 1981; Zar, 1974). The following parameters will be used in evaluating the homing performance of the mice. A sample analysis will yield a mean vector, $\mathbf{m}$. This $\mathbf{m}$ is defined by its polar coordinates: $\phi$ and $r$, where $\phi$ is the sample mean direction, and $r$ is the length of $\mathbf{m}$. The mean vector length, $r$, serves as a measure of concentration as well as dispersion. The larger $r$ is, the less dis- 
persed the directions are around the mean angle, $\phi$. The angle of deviation for the confidence interval, $\delta$, is used to determine the confidence limits $(\phi+\delta)$, which in turn are used to determine whether the sample mean angle, $\phi$, differs significantly from the home direction azimuth. To determine the confidence limits in the present report, I chose the confidence coefficient, $Q$, to be 0.99 . This coefficient is the probability that the unknown sample mean angle, $\phi$, will lie within the confidence interval.

The Mann-Whitney test (Siegel, 1956) was used to evaluate group-specific differences in the time spent and distance covered in order to reach the nest from the center of the arena.

Questions regarding specific manipulations will be explained in the context of the particular experiments.

\section{EXPERIMENT 1}

The first task was to find out whether mice could integrate a path during passive displacement over a distance of $75 \mathrm{~cm}$. Each of 10 mice was taken directly from its holding cage to the testing room, where it was immediately placed into the nest box attached to the circular test arena. Seven mice were pregnant, and 3 had pups. The exit hole close to the periphery of the arena was surrounded by a Plexiglas cylinder $(10 \mathrm{~cm}$ in diameter $X$ $10 \mathrm{~cm}$ in height) that prevented the mouse from moving across the arena, but allowed visual scanning in all directions. The mouse had enough space inside the cylinder to stand on its hind feet and move around. Each mouse was left in this situation for $45-120 \mathrm{~min}$ prior to testing, during which the mice could be seen coming to the surface and exploring.

To test for passive path integration after this brief habituation period, the mouse, while outside the nest, was quickly seized by the base of its tail with $30-\mathrm{cm}$-long forceps, or by hand, and displaced straight to the center of the arena. The arena was immediately rotated $90^{\circ}$ clockwise or counterclockwise around the mouse that was held above the center. The rotation of the arena served as a control for intra-arena cues. Then the mouse was allowed to depart, and the direction of its arrival at a point $5 \mathrm{~cm}$ from the arena periphery was recorded. The experimenter's position was $90^{\circ}$ from the nest position.

Most of the mice, upon being released, moved quickly without turning for about $10-15 \mathrm{~cm}$ in the direction in which they were facing. The mice would then stop for a few seconds and sometimes make one to two full turns in place before proceeding to the periphery of the arena. To control for the effect of this bias on the general direction taken by the mice, one group of 10 mice (Group Snout In) was placed with their snouts pointing to the nest, and another group of mice had its snouts pointing in a direction opposite to the nest (Group Snout Out).

Another source of potential bias was the nest position on the side opposite to the windows. Thus, when released from the center, the mice might systematically orient away from the bright lights coming from the windows. To control for this potential systematic error, for a third group of 10 mice (Group Light Facing), the nest position was on the opposite side of the arena, close to the windows. In this case, the mice had to face and move toward the lights to home from the nest to the center. The mice in this experiment were placed in the center with their snouts facing the nest.

Finally, after conducting the above experiments, I noticed that most of the arrival points of the mice were to the side of the nest away from where the experimenter stood. Each of 10 additional mice was displaced to the center with its snout pointing to the nest. The experimenter's position in this experiment, however, was right behind the nest (Group Sapiens Facing). The hypothesis was that if the position of the experimenter caused the mice to arrive at the opposite side, in this experiment, an equal number of mice would arrive at each side of the nest.

\section{Results}

For the 10 mice in Group Snout In, the mean direction of the sample, $\phi$, was $33.0^{\circ}$ (see Figure 2 ); the mean vector length, $r$, was 0.72 . Thus, the mice had a significant directional tendency ( $v$ test, homeward component; $v=$ $0.604, .005<p<.001$ ). The angle of deviation, $\delta$, is about $49^{\circ}$ - that is, the mean angle falls between the two confidence limits of $344^{\circ}<\phi<82^{\circ}$ (confidence coefficient, $Q,=0.99$ ). Therefore, the mean angle of $33^{\circ}$ does not differ significantly from the azimuth of the home (nest) direction $\left(h=0^{\circ}\right)$.

For the 10 mice in Group Snout Out, $\phi=39.7^{\circ}$ and $r=$ 0.65 (Figure 2). The mice had a significant directional tendency $(v=0.51, .05<p<.01)$. The two confidence limits are $339.7^{\circ}<\phi<99.7^{\circ}\left(\delta=60^{\circ}, Q=0.99\right)$. There-
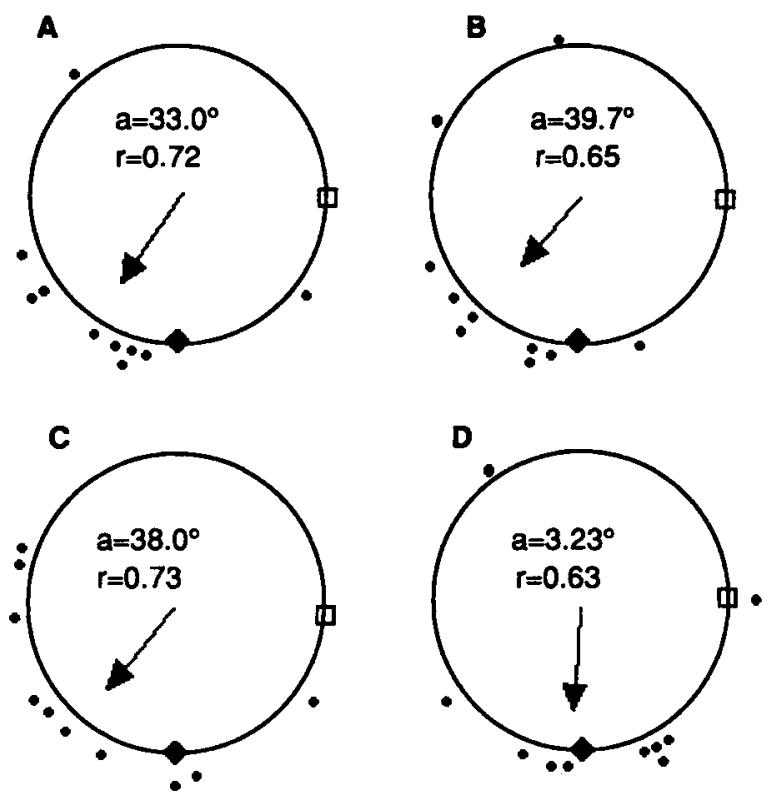

Figure 2. Experiment 1. Mice were passively displaced from the nest to the center of the arena. The polar histograms show the distribution of arrival points from the edge of the arena for mice in Groups A (Snout In), B (Snout Out), C (Light Facing), and D (Sapiens Facing). The filled rhombus represents the prentation nest location at $0^{\circ}$. The open square represents the postrotation nest location at $90^{\circ}$. The mean angle of each distribution $(a)$ is shown by the arrow, and the degree of clustering of the distribution $(r)$ is shown by the relative length of the arrow relative to the radius. (For additional explanation, see text.) 
fore, the mean angle of $39.7^{\circ}$ does not differ significantly from the azimuth of the home direction.

For the 10 mice in Group Light Facing, $\phi=38.0^{\circ}$ and $r=0.73$ (Figure 2). The mice had a significant directional tendency $(v=0.575, .005<p<.001)$. The two confidence limits are $350.0^{\circ}<\phi<86.0^{\circ}\left(\delta=48^{\circ}\right.$, $Q=0.99$ ). Therefore, the mean angle of $39.7^{\circ}$ does not differ significantly from the azimuth of the home direction.

For the 10 mice in Group Sapiens Facing, $\phi=3.2^{\circ}$ and $r=0.63$ (Figure 2). The mice had a significant directional tendency $(v=0.63, .005<p<.001)$. The two confidence limits are $301.2^{\circ}<\phi<65.2^{\circ}\left(\delta=62.0^{\circ}, Q=\right.$ 0.99 ). Therefore, the mean angle of $38.0^{\circ}$ does not differ significantly from the azimuth of the home direction.

\section{EXPERIMENT 2}

The objective of Experiment 2 was to find out whether viewing the environment only from the location of the nest entrance would result in the mouse's acquiring a representation that would allow it to exhibit perceptual vector deduction when placed $75 \mathrm{~cm}$ away from the nest entrance.

Each of 7 experimental mice was taken from its holding cage and placed directly into the nest box of the experimental arena. A clear Plexiglas cylinder $(10 \times$ $10 \mathrm{~cm}$ ) was again placed on top of the nest entrance. Each mouse was left in this situation for $24 \mathrm{~h}$. The next day, the mouse was transferred to the center in a way that eliminated passive path integration (see General Method section). Then the path length, duration, and final direction were recorded (as described in Data Analysis).

\section{Results}

For the 7 mice, $\phi=85.12^{\circ}$ and $r=0.307$ (see Figure 3). The null hypothesis of random directional choice cannot be rejected (Rayleigh test, $R=2.15, p>.5$ ).

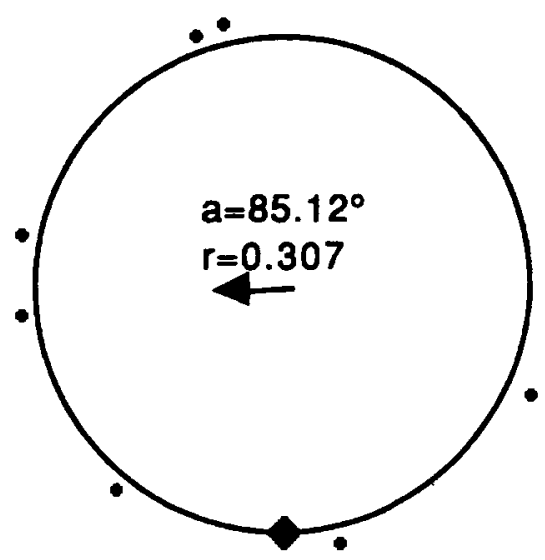

Figure 3. Experiment 2. Directional orientation of homing mice displaced to the center of the arena after they had had a 24-h scanning exploration period. Symbols as in Figure 2. (For additional information, see text.)

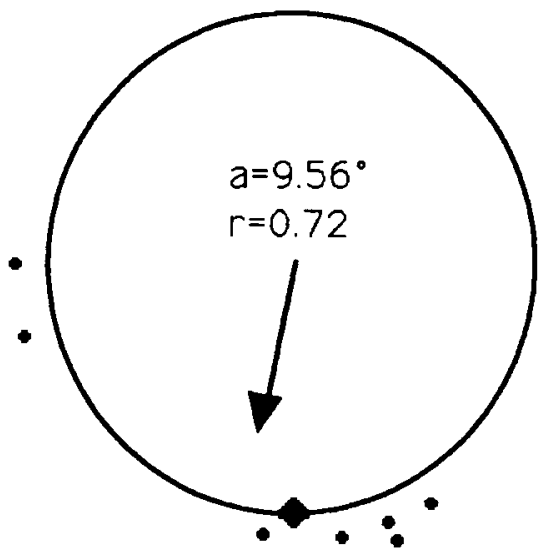

Figure 4. Experiment 3. Directional orientation of homing mice displaced to the center of the arena after they had had a 24-h free exploration period. Symbols as in Figure 2. (For additional information, see text.)

The mean time taken by the mice to reach the nest was $58.8 \pm 44.55 \mathrm{sec}$ (standard deviation, or $S D$ ). The mean length of the path the mice took to reach the nest was $517 \pm 197.1 \mathrm{~cm}(S D)$.

\section{EXPERIMENT 3}

The objective of this experiment was to find out whether free exploration of the whole arena was sufficient for an apparent perceptual deduction of homing vector.

Each of 7 experimental mice was introduced to the nest of the test arena and left there for $24 \mathrm{~h}$. The mice in this experiment had free access to the whole arena, which they all explored. At the end of this period, each mouse was removed from the nest and transferred to the center of the arena with the procedure to eliminate passive path integration (see General Method). Data were collected as described in Data Analysis.

\section{Results}

For the 7 mice, $\phi=9.56^{\circ}$ and $r=0.72$ (see Figure 4). The mice had significant directional preference $(v=$ $0.71, p<.005$ ).

The mean time taken by the mice to reach the nest was $16.33 \pm 6.5 \mathrm{sec}(S D)$. This was significantly less than the mean time taken by the mice in Experiment 2 (MannWhitney test, $p=.012$, two-tailed). The mean length taken to reach the nest was $239.4 \pm 107.9 \mathrm{~cm}(S D)$. This was significantly different from that taken by the mice in Experiment 2 (Mann-Whitney test, $p=.014$, two-tailed).

\section{EXPERIMENT 4}

The objective of this experiment was to investigate the effect of shuttling between a distal goal and the home base on the subsequent accuracy of homing as compared with the effect of only free exploration on subsequent homing. 
Each of 7 experimental mice was taken from the housing cage and placed into the nest, where it had free access to the arena for $24 \mathrm{~h}$. At the end of this period, pups were removed from the nest and laid down in a line leading from the nest to the center. Thereafter, the mouse was allowed to retrieve the pups from the center of the arena for 10-15 times (see Alyan \& Jander, 1994). The mouse was then transferred from the nest to the center of the arena by the method preventing passive path integration (see General Method). One difference from the procedure of Experiment 3 was that the arena was rotated $90^{\circ}$ clockwise or counterclockwise relative to the training orientation. This served as a control for the possibility that the shuttling mice might use intra-arena cues to go back to the nest. The homing data of the departing mouse were then recorded.

\section{Results}

For the 7 mice, $\phi=6.7^{\circ}$ and $r=0.73$ (see Figure 5). The mice had a significant directional tendency $(v=$ $0.73, p<.005$ ).

The mean time taken by the mice to reach the nest was $14.12 \pm 5.9 \mathrm{sec}(S D)$. The mean length taken to reach the nest was $171.2 \pm 68.3 \mathrm{~cm}(S D)$. It is important to mention that 2 of the mice indirectly reached the new, rotated nest location without passing through the original nest location. However, I believe that this could not have biased the path length and latency data in any significant way, because adding the amount of time and distance of travel between the new and original nest location would have slightly increased the obtained values.

The angular deviation from the mean angle taken by the mice in this experiment was not significantly different from the equivalent value of the mice that had had only exploration experience with no retrieval (Experiment 3, nonparametric test for dispersion, $p=.267$, one-tailed). That is, homing performance for the mice in the two groups did not differ significantly (Batschelet, 1981). The null hypothesis that both groups of mice did

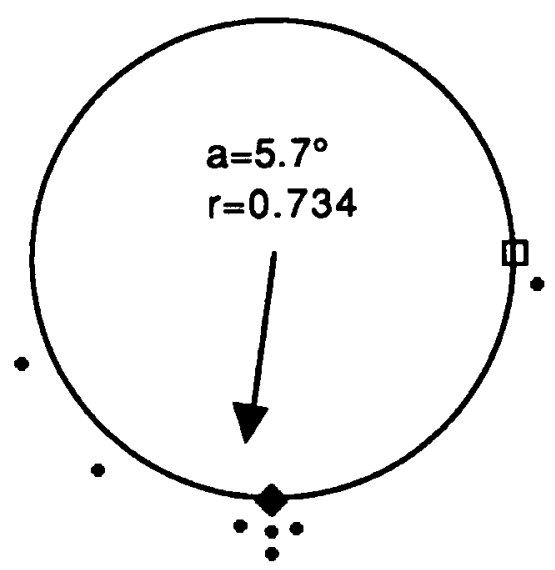

Figure 5. Experiment 4. Directional orientation of homing mice displaced to the center of the arena after they had had a 24-h free exploration period and retrieved 10 pups. Symbols as in Figure 2. (For additional information, see text.) not differ with regard to their dispersion around the sample mean angle cannot be rejected.

The mean time taken by the mice to get home in this experiment was not significantly different from that of the mice that had explored the arena for $24 \mathrm{~h}$ without retrieval (Mann-Whitney test, $p=.79$, two-tailed). An analogous conclusion can be drawn about the distances traveled (Mann-Whitney test, $p=.28$, two-tailed).

\section{EXPERIMENT 5}

This experiment had two objectives. The first, and main, objective was to investigate the effects of letting the mice explore a large arena as well as the effects of subjecting them to the elimination of the passive path integration procedure one time before being tested in another arena. This procedure was adopted after Keith and McVety (1988). Keith and McVety claimed that subjecting the rats to the procedural aspect of the task would presumably facilitate building a cognitive map of the room layout and, therefore, support perceptual vector deduction. Second, I assumed that allowing a mouse to freely explore a constellation of visual landmarks from an arena in one part of the room affects the landmark orientation in a nearby second arena. In this second arena, the mouse could explore the same landmarks, but only by scanning from the nest. In other words, would the information about the visual environment, gained while moving in one part of that environment, support perceptual vector deduction when the animal is transferred to another part of the same environment? The test here was to find out if the mouse's cognitive representation of landmarks from one part of the room would facilitate perceptual vector deduction ability in an adjacent part. This is because it would need only to realign its already built representation of the room when confined to the nest location and compute a vector toward the nest from a novel point.

To this end, each of 7 experimental mice was introduced to the table arena, which was located about $1.2 \mathrm{~m}$ from the circular test arena used in the previous experiments (see Arena and Surroundings). After $24 \mathrm{~h}$ of exploration on the table arena, the mouse was subjected to the procedure of eliminating passive path integration. Then the mouse was released back onto the table arena, close to the center, after lowering a pup into the box. Immediately after the mouse arrived at the nest under the table arena, it was transferred to the circular test arena's nest. The nest hole was surrounded with a Plexiglas cylinder, $10 \times 10 \mathrm{~cm}$. Then the procedure of Experiment 2 was followed. Data were collected as in Experiment 2.

\section{Results}

For the 7 mice, $\phi=136.4^{\circ}$ and $r=0.29$ (see Figure 6). The null hypothesis of random orientation cannot be rejected (Rayleigh test, $R=2.03, p>.5$ ).

The mean time taken by the mice to reach the nest was $32.6 \pm 12.68 \mathrm{sec}(S D)$; the mean length of the path was $355.6 \pm 141.0 \mathrm{~cm}(S D)$. 


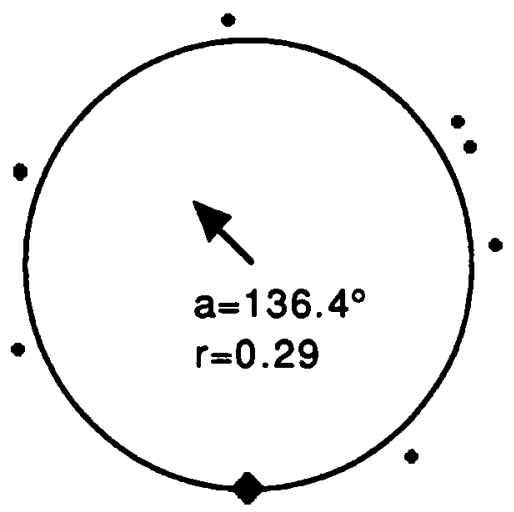

Figure 6. Experiment 5. Directional orientation of homing mice displaced to the center of the arena after they had had a 24-h free exploration period and had been subjected to the test procedure on a table arena. Symbols as in Figure 2. (For additional information, see text.)

The mean time taken by this group to reach its nest was significantly (Mann-Whitney test, $p=.006$, twotailed) different from that taken by the mice after $24 \mathrm{~h}$ of free exploration in the circular arena. However, the mean distance traveled by both groups was not significantly different ( $p=.51$, one-tailed).

\section{DISCUSSION}

The objectives of this discussion are (1) to discuss the results obtained with regard to perceptual vector deduction in the house mouse; and (2) to appraise the role of active and passive path integration in deducing a homing vector.

The results obtained in this study provide evidence that the mice were not capable of perceptual vector deduction. This, however, should not be taken to mean that mice are not capable of forming a cognitive representation of the spatial layout of their environment. On the other hand, the mice were capable of integrating a passive displacement over a distance of $75 \mathrm{~cm}$. The homing performance of the mice after a passive displacement from the nest to the center of the arena was better than the homing by the mice that could view the environment only from the nest and were displaced over a circuitous route. However, after the mice had freely explored the whole arena by walking for $24 \mathrm{~h}$, they were able to navigate in the home direction solely by using landmarks. Their directional accuracy was low. The standard of comparison for accurate homing is the performance of the mice after they had experienced repetitive shuttling locomotion between their nest and the center of the arena (Alyan \& Jander, 1994). The mean angle for the homing vector in this situation was $0.11^{\circ} \pm 4.58^{\circ}(S D ; n=44)$; the mean time taken to reach home was $2.41 \pm 1.13 \mathrm{sec}$ $(S D ; n=35)$, and the mean distance taken to reach home was $79.56 \pm 11.57 \mathrm{~cm}(S D ; n=11)$.

Providing the mice with the 10 shuttling experiences between the nest and the center of the arena did not increase the accuracy of their homing vector, as compared with the mice with only $24-\mathrm{h}$ exploratory experience. Finally, the experience of free exploration in one part of an environment, as well as the experience of certain procedural aspects of the test trials, did not result in differential performance that would have indicated a capacity to perceptually deduce the direction of a homing vector.

In the following sections, I shall discuss the relevance of the individual experiments for vector computation. The conclusions will be compared with those in the pertinent literature.

\section{Passive Directional Path Integration in Mice}

The results of the first experiment corroborate the previous conclusion (Alyan \& Jander, 1994) that mice are capable of deducing a homing vector by integrating the directional component of passive displacement. The mean homing direction taken by passively displaced mice to a novel location indicated that they were well oriented and did not deviate significantly, on average, from the homeward direction. The mice were consistently oriented homeward, regardless of the directional placement of their bodies or the direction of the window lights with respect to the home vector. This first demonstration of passive path integration in the house mouse (Mus musculus) confirms similar conclusions based on experiments with the hamster (Mesocricetus auratus), the gerbil (Meriones unguiculatus), and the rat (Rattus norvegicus) (Etienne, 1980, 1992; Matthews, Campbell, \& Deadwyler, 1988; H. Mittelstaedt \& M. L. Mittelstaedt, 1982; Potegal, 1982).

Most homing directions taken by the mice in the first three groups of Experiment 1, were biased to the right (from their perspective) of the nest entrance (Figure 2). An explanation for this bias might be the position of the experimenter during these trials on the side that the mice appeared to avoid. A control experiment with the experimenter standing on the opposite side would have helped in evaluating this hypothesis. This I tried repeatedly, but failed because I am right-handed. However, the fourth group of mice (Sapiens Facing) that was displaced while the experimenter was standing behind the nest homed symmetrically around the nest. This indicates that the position of the experimenter might have had a repellant effect, albeit not a significant one, on the homing direction of the mice. Another possible explanation for such bias could be the way the mice were held at the center while rotating the arena $90^{\circ}$. It is possible that the orientation of the mouse's body was shifted.

The well-controlled homing orientation in the first experiment might be interpreted as evidence for either perceptual deduction of a homing vector or passive path integration. On the basis of other results from experiments under different conditions (see below), the latter is more likely. Similarly, passive path integration during multiple passive transport, a procedure frequently employed with rats in the Morris water tank, is a plausible explanation for their homing performance from novel starting locations (see also Benhamou, Sauve, \& Bovet, 1990). The effect of multiple passive transport on pas- 
sive path integration was not investigated in the present experiments.

\section{Latent Learning}

Keith and McVety (1988) hypothesized that after rats are simply placed on the underwater platform in a Morris water tank, they might be able to form a cognitive map of the surrounding visual environment. At a later time, such a cognitive map could enable them to generate a homing trajectory from a novel starting location at the periphery of the tank, which then would have been an instance of instantaneous transfer. This form of latent learning (Tolman, 1948) would imply their ability to generate a solution to a novel problem on the basis of information acquired at a previous time, with no apparent reinforcement. The cited water maze performance indicated that the rats exhibited some form of latent learning (Keith \& McVety, 1988). Similarly, Chew et al. (1989) found that placing the rats on the platform results in improved, although not accurate, return performance (see also Sutherland et al., 1987; Sutherland \& Dyck, 1984; Sutherland \& Linggard, 1982; Whishaw, 1991). This also indicated that the rats learned something latently: They acquired some representation of the environment that was sufficient to facilitate homing from a novel vantage point in shorter time, as compared with rats never placed on the platform. This, however, is not sufficient evidence for perceptual vector deduction (Chew et al., 1989).

On the other hand, mice deprived of the benefit of passive path integration, after having had plenty of opportunity to view the surrounding environment from only the home base, homed most poorly in Experiment 2 . The performance failed to indicate any ability to perceptually deduce a homing vector from a novel vantage point. Moreover, the results of Experiment 2 failed to indicate that any latently acquired information at the home base could be of appreciable benefit to the mice (for similar conclusions for rats, see Ellen, 1980; Ellen, Soteres, \& Wages, 1984; Herrmann, Bahr, Bremner, \& Ellen, 1982). In sum, there was no indication of improved performance of homing in terms of directionality, latency, or directness when returning to the nest, based on preceding exploratory scanning, as compared with the performance of the mice that explored the whole arena (see below).

Experiment 5 corroborates the conclusion that mice do not perceptually deduce a homing vector. The mice in this experiment had ample opportunity to freely explore part of the visual environment. They were then transferred to another arena, where they could scan the same environment from a different vantage point. Their homing was better in terms of time taken and distance covered to reach the goal, when compared with their homing after only scanning exploration of the environment, restricted to the nest entrance (Experiment 1). Still, the homing orientations of the mice in Experiment 5 were not accurate, especially in terms of final directions taken to reach home. Therefore, their knowledge about the procedural aspects of the test (being in a large arena and subjected to elimination of the passive path integration procedure) was not a sufficient requirement for accurate homing (for similar conclusions on rats, see Chew et al., 1989; Sutherland et al., 1987; Sutherland \& Dyck, 1984; Sutherland \& Linggard, 1982; Whishaw, 1991). This contrasts with the conclusion reached by Keith and McVety (1988) for the rat.

In addition, it appears that the information gained by the mice about the environment, as a result of moving through a part of that environment, was not "transferrable" to another part of the same environment. The mice appear to have treated the two nearby arenas as if they were located in somewhat different environments (for similar conclusions for rats, see Ellen, 1980; Ellen \& Weston, 1983). However, the results do not completely rule out some latent learning. The fact that the performance of the mice in Experiment 5 was better than performance in Experiment 1 could be due to two factors-either the mice gained knowledge about the procedural aspects of the test, or they gained knowledge about the environment while freely moving in one part of it. Experiment 5 does not allow the assessment of the contribution of either experience to such facilitation.

In conclusion, the mice did not exhibit any evidence for perceptual vector deduction under the present experimental conditions. Also, this is not contradicted by work with other rodents. Acquaintance with the procedures that were used later to test for perceptual vector deduction, as well as the ability to move freely in one part of the environment (Experiment 5), seemed to have slightly facilitated homing performance in the mice. This slightly improved homing performance was not comparable to the substantial improvement observed for rats in the Morris water tank (Keith \& McVety, 1988; Whishaw, 1991). This difference could be due to differences in the procedures used in the Morris water tank and those used here, differences in motivational states, differences between species tested, or to the involvement of passive path integration in orienting rats in the Morris water tank.

\section{Role of Active Movement}

The mice that had ample opportunity to freely explore the arena (Experiment 3) were better oriented than were those without exploratory experience. The mean latency and distance taken to reach the nest were much lower than the values obtained for the mice in Experiment 2 . Thus, exploring the arena and viewing the room from different locations while moving seem to be necessary requirements for mice as well as for rats (Chew et al., 1989; Sutherland et al., 1987; Whishaw, 1991) to be fairly oriented.

It seems surprising that shuttling the mice 10-20 times between the nest and the center of the arena after a 24-h exploratory experience did not significantly improve the accuracy of the homing orientation (Experiment 4). This brief experience with the path to be taken did little to improve the directional accuracy of homing and the time and distances taken to reach the nest, as opposed to the mice that only explored the arena (Experi- 
ment 3). This result only stresses for the mouse what Whishaw (1991) has already pointed out for the ratthat more accurate navigation is a consequence of the experience the animal had in moving between two goals. A more extensive experience could conceivably result in more accurate homing between two points (Alyan \& Jander, 1994).

The findings of Experiments 1 and 3 with mice partially support the hypothesis of Sutherland et al. (1987) and Chew et al. (1989) for the rat-that the ability to generate a novel trajectory is conditional upon first viewing and then moving through the environment. This hypothesis implies the ability of rats to associate local views experienced while moving through the environment with the movement patterns generated during movement (for a detailed argument, see McNaughton, 1989; Sutherland \& Rudy, 1989).

Also, for some invertebrates, active movement through an area seems necessary for good homing performance based on landmark orientation within that area. In recent years, Gould (1986, 1990), Dyer (1993), and Dyer, Berry, and Richard (1993) reported that honeybees appeared to be capable of recognizing familiar landmarks from novel vantage points and of generating homing vectors from such novel vantage points (Dyer, 1993). However, prior to these experiments, the bees had ample opportunity to explore the environment. What is considered a novel vantage point by the experimenter might not be so for the animal.

The evidence obtained in Experiments 2-4 seems to contradict the proposition that an animal can form a cognitive map of the environment from a limited view of the environment (Keith \& McVety, 1988). It is clear from the present results with mice, as well as from those obtained with mice and rats, that rodents gradually learn about their home ranges after extensive training (Alyan \& Jander, 1994; Chew et al., 1989; Ellen et al., 1984; Morris, 1981, 1983; Sutherland et al., 1987; Whishaw, 1991, to cite only a very few articles).

Moreover, O'Keefe and Nadel (1978, see also Nadel, 1991, 1992; O'Keefe, 1990, 1991b) hypothesized that an all-or-none form of map learning takes place during exploration. With such a map, rats should easily and accurately generate or remember a vector from one place to another with high accuracy. However, Ellen and his colleagues provided evidence inconsistent with such a hypothesis (Ellen, 1980; Ellen \& Weston, 1983). Ellen and Weston found that, although learning the spatial relations among tables during an exploratory period may be necessary for navigation between two points, it is not sufficient for successful performance. Their findings with rats are consistent with the present findings with mice-homing accuracy after free exploration and little shuttling experience was low (Experiments 3 and 4; see also Alyan \& Jander, 1994).

In conclusion, the mice in Experiments 2, 3, and 4 were able to home more accurately after actively exploring the whole arena than after only scanning the environment from the nest site. Movement between the center of the arena and the nest did not result in homing that was significantly more accurate than that after only exploration. The results are in accordance with conclusions reached about rats in the Morris water tank: Good homing performance requires that the animal had moved through the environment (Chew et al., 1989).

\section{REFERENCES}

Alyan, S., \& JANDER, R. (1994). Short-range homing in the house mouse, Mus musculus: Stages in the learning of directions. Animal Behaviour, 48, 285-298.

BARNes, C. A. (1988). Spatial learning and memory processes: The search for their neurobiological mechanism in the rat. Trends in Neuroscience, 11, 163-170.

BatsChelet, E. (1981). Circular statistics in biology. London: Academic Press.

Benhamou, S., Sauve, J. P., \& Bovet, P. (1990). Spatial memory in large scale environments: Efficiency and limitation of the egocentric coding process. Journal of Theoretical Biology, 145, 1-12.

Chew, G. L., Sutherland, R. J., \& Whishaw, I. Q. (1989). Latent learning does not produce instantaneous transfer of place navigation: A rejoinder to Keith and McVety. Psychobiology, 17, 207209.

DYER, F. C. (1993). How honeybees find familiar feeding sites after changing nesting sites with a swarm. Animal Behaviour, 46, 813-816.

DYER, F. C., BERRY, N. A., \& RiCHARD, A. S. (1993). Honeybee spatial memory: Use of route-based memories after displacement. Animal Behaviour, 45, 1028-1030

Eichenbaum, H., Stewart, C., \& Morris, R. G. M. (1990). Hippocampal representation in place learning. Journal of Neuroscience, 10, 3531-3542.

Ellen, P. (1980). Cognitive maps and the hippocampus. Physiological Psychology, 8, 168-174.

Ellen, P., Soteres, B. J., \& Wages, C. (1984). Problem solving in the rat: Piecemeal acquisition of cognitive maps. Animal Learning \& Behavior, 12, 232-237.

Ellen, P., \& Weston, S. L. (1983). Problem solving in the rat: Septal lesion effects on habituation and perseverative tendencies. Physiological Psychology, 11, 112-118.

ETIENNE, A. S. (1980). The orientation of the golden hamster to its nest-site after the elimination of various sensory cues. Experientia, 36, 1048-1050.

ETIENNE, A. S. (1992). Navigation of a small mammal by dead reckoning and local cues. Current Directions in Psychological Science, 1, 48-52.

Etienne, A. S., Hurni, C., Maurer, R., \& Seguinot, V. (1991). Twofold path integration during hoarding in the golden hamster? Ethology, Ecology \& Evolution, 3, 1-11.

Etienne, A. S., LAmbert, S. J., Reverdin, B., \& Teroni, E. (1993). Learning to recalibrate the role of dead reckoning and visual cues in spatial navigation. Animal Learning \& Behavior, 21, 266-280.

ETIENNE, A. S., MAURER, R., \& SAUCY, F. (1988). Limitations in the assessment of path dependent information. Behaviour, 106, 81-111.

Etienne, A. S., Teroni, E., Hurni, C., \& Portenier, V. (1990). The effect of a single light cue on homing behaviour of the golden hamster. Animal Behaviour, 39, 17-41.

etienne, A. S., Teroni, E., Maurer, R., Portenier, V., \& Saucy, F. (1985). Short-distance homing in a small mammal: The role of exteroceptive cues and path integration. Experientia, 41, 122-125.

Gallistel, C. R. (1990a). The organization of learning. Cambridge, MA: MIT Press.

GALLISTEL, C. R. (1990b). Representations in animal cognition: An introduction. Cognition, 37, 1-22.

Gould, J. L. (1986). The locale map of honeybees: Do insects have cognitive maps? Science, 232, 861-863.

Gould, J. L. (1990). Honeybee cognition. Cognition, 37, 83-103.

Herrmann, T., Bahr, E., Bremner, B., \& Ellen, P. (1982). Problem solving in the rat: Stay vs. shift solutions on the three-table task. Animal Learning \& Behavior, 10, 39-45. 
Keith, J. R., \& MCVety, K. M. (1988). Latent place learning in a novel environment and the influences of prior training in rats. Psychobiology, 16, 146-151.

Matthews, B. L., Campbell, K. A., \& Deadwyler, S. A. (1988). Rotational stimulation disrupts spatial learning in fornix-lesioned rats. Behavioral Neuroscience, 102, 35-42.

MCNAughton, B. L. (1989). Neuronal mechanisms for spatial computation and information storage. In L. Nadel, L. A. Cooper, P. Culicover, \& R. M. Harnish (Eds.), Neural connections, mental computation (pp. 284-350). London: MIT Press.

Mittelstaedt, M. L., \& Mittelstaedt, H. (1980). Homing by path integration in a mammal. Naturwissenschaften, 67, 566.

Mittelstaedt, H., \& MittelstaedT, M. L. (1982). Homing by path integration. In F. Papi \& H. G. Wallraff (Eds.), Avian navigation (pp. 290-297). Berlin: Springer-Verlag.

MoRRIs, R. G. M. (1981). Spatial localization does not require the presence of local cues. Learning \& Motivation, 12, 239-260.

MorRIs, R. G. M. (1983). An attempt to dissociate "spatial-mapping" and "working memory" theories of hippocampal function. In W. Seifert (Ed.), Neurobiology of the hippocampus (pp. 405-432). New York: Academic Press.

MoRRIS, R. G. M. (1984). Development of a water-maze procedure for studying spatial learning in the rat. Journal of Neuroscience Methods, 11, 47-60.

NADEL, L. (1991). The hippocampus and space revisited. Hippocampus, 1, 221-229.

NADEL, L. (1992). Multiple memory systems: What and why. Journal of Cognitive Neuroscience, 4, 179-188.

O'KeEFE, J. (1990). A computational theory of the hippocampal cognitive map. In J. Storm-Mathisen, J. Zimmer, \& O. P. Ottersen (Eds.) Progress in brain research: Vol. 83. Understanding the brain through the hippocamus: The hippocampal region as a model for studying brain structure and function (pp. 301-312). New York: Elsevier.

O'KEEFE, J. (1991a). An allocentric spatial model for the hippocampal cognitive map. Hippocampus, 1, 230-235.

O'KeEFE, J. (1991b). The hippocampal cognitive map and navigational strategies. In J. P. Paillard (Ed.), Brain and space (pp. 273-295). New York: Oxford University Press.

O'KeEFE, J., \& NADEL, L. (1978). The hippocampus as a cognitive map. New York: Oxford University Press, Clarendon Press.

O'KeEFe, J., \& NADEL, L. (1979). Précis of O'Keefe \& Nadel's The hippocampus as a cognitive map. Behavioral \& Brain Sciences, 2 , 487-533.

Potegal, M. (1982). Vestibular and neostriatal contributions to spa- tial orientation. In M. Potegal (Ed.), Spatial abilities (pp. 361-387). New York: Academic Press.

Schenk, F., \& MORRIS, R. G. M. (1985). Dissociation between components of spatial memory in rats after recovery from the effects of retrohippocampal lesions. Experimental Brain Research, 58, 128

SIEGEL, S. (1956). Nonparametric statistics. London: McGraw-Hill.

STAHL, J. M., \& ElLEN, P. (1974). Factors in the reasoning performance of the rat. Journal of Comparative \& Physiological Psychology, 20, 26-32.

Sutherland, R. J., Chew, G. L., Baker, J. C., \& Linggard, R. C. (1987). Some limitations on the use of distal cues in place navigation by rats. Psychobiology, 15, 48-57.

SuTHERLAND, R. J., \& DYCK, R. H. (1984). Place navigation by rats in a swimming pool. Canadian Journal of Psychology, 38, 322-347.

Sutherland, R. J., \& LingGard, R. (1982). Being there: A novel demonstration of latent spatial learning. Behavioral \& Neural Biology, 36, 103-107.

SuTHERLAND, R. J., \& MCDONALD, R. J. (1990). Hippocampus, amygdala, and memory deficits in rats. Behavioral Brain Research, 37, 57-79.

Sutherland, R. J., \& Rudy, J. W. (1989). Configural association theory: The role of the hippocampal formation in learning, memory, and amnesia. Psychobiology, 17, 129-144.

Tolman, E. C. (1948). Cognitive maps in rats and men. Psychological Review, 55, 189-208.

WEHNER, R. (1983). Celestial and terrestrial navigation. In F. Huber \& H. Markl (Eds.), Neuroethology and behavioral physiology (pp. 366381). Berlin: Springer-Verlag.

WehneR, R., \& SRINIVASan, M. V. (1981). Searching behaviour of desert ants, genus Cataglyphis (Foramicidae, Hymenoptera). Journal of Comparative Physiology A, 142, 315-338.

WEHNER, R., \& WEHNER, S. (1990). Insect navigation: Use of maps or Ariadne's thread? Ethology, Ecology \& Evolution, 2, 27-48.

WhISHAW, I. Q. (1991). Latent learning in a swimming pool place task by rats: Evidence for the use of associative and not cognitive mapping processes. Quarterly Journal of Experimental Psychology, 43B, 83-103.

Whishaw, I. Q., \& MitTleman, G. (1986). Visits to starts, routes and places by rats (Rattus norvegicus) in a swimming pool navigation task. Journal of Comparative Psychology, 100, 422-431.

ZAR, J. H. (1974). Biostatistical analysis. London: Prentice-Hall.

(Manuscript received March 1, 1994; revision accepted for publication August 17, 1994.) 